\title{
SHRIMP AND FISH CATCH LANDING TRENDS IN SONGKHLA LAGOON, THAILAND DURING 2003-2016
}

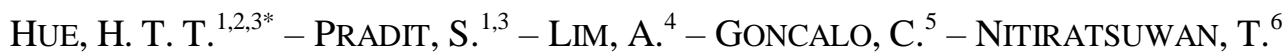 \\ ${ }^{1}$ Marine and Coastal Resources Institute, Prince of Songkla University (MACORIN) \\ Hat Yai, Songkhla 90112, Thailand \\ ${ }^{2}$ Central Institute for Natural Resources and Environmental Studies, Vietnam National \\ University, Ha Noi, Vietnam \\ ${ }^{3}$ Coastal Oceanography and Climate Change Research Center, Prince of Songkla University, \\ Hat Yai, Songkhla, Thailand \\ ${ }^{4}$ Faculty of Science and Technology, Prince of Songkla University \\ Pattani, Thailand \\ ${ }^{5}$ NIRAS Sweden AB, Stockholm, Sweden \\ ${ }^{6}$ Rajamangala University of Technology Srivijaya, Trang, Thailand \\ *Corresponding author \\ e-mail: hathithuhue2001@yahoo.com; phone: +66-0910495786 \\ (Received $14^{\text {th }}$ Mar 2018; accepted $21^{\text {st }}$ May 2018)
}

\begin{abstract}
Time series analysis techniques and Seasonal Autoregressive Integrated Moving Average (SARIMA) models were used to analyze monthly fish and shrimp catch landing trends recorded for Songkhla shallow lagoon in Thailand (2003-2016). Autocorrelation (AC) and Partial Autocorrelation (PAC) functions were calculated to build seasonal ARIMA models. These models were well-chosen for explaining the time series and forecasting future catch landings. It is found that both fish and shrimp catch landings tend to fluctuate steadily. The fish catch from 2017 to 2020 is steadily increasing on the average catch for the period $2003-2016$ by up to $36.06 \%$, while the shrimp catch is decreasing by around $15.47 \%$ for the same period. This study demonstrates the importance of undertaking detailed studies of ecological and economic sustainable development to support the comprehensive fisheries management policy for Songkhla Lagoon. The present study shows an effective tool for making accurate forecasts; it also helps in decision making about, and fisheries management of the Songkhla Lagoon.
\end{abstract}

Keywords: seasonal ARIMA models, artificial neural networks, time series forecasting, fishery trend, Songkhla lagoon

\section{Introduction}

Time series analysis of fishery landings plays a vital role in fisheries management and decision making due to its capacity for demonstrating the trends and seasonality patterns of the data (Koutroumanidis et al., 2006; Tsitsika et al., 2007). In the fishery field, time series analysis qualifies for forecasting because it expresses past patterns and projects into the future (Stergiou et al., 1997).

Forecasting has been applied to all sectors of the economy. During the last three decades, forecasting has been rapidly developing in the field of fisheries, in describing fishery units (Murawski et al., 1983) and the state of fisheries' resources and management (Fox, 1970; Pauly, 1989; Sparre et al., 1989; Stergiou and Petrakis, 1993). Various statistical models have been used to analyze trends and to forecast fish catches. 
Significant regression, univariate and multivariate time series models were used to forecast monthly and annual marine fisheries' catches (Stergiou and Christow, 1996; Stergiou et al., 1997) of Loliginid and Ommastrephid (Georgakarakos et al., 2002, 2006).

The forecasting of fisheries' landings has been studied by many researchers using the Autoregressive Integrated Moving Average (ARIMA) methodology. So far, this method has been successful in describing and forecasting fishery dynamics of broadly different species-significantly, demersal and pelagic species (Stergiou, 1990; Stergiou and Christow, 1996; Stergiou et al., 1997; Tsitsika et al., 2007), squid (Pierce and Boyle, 2003), mackerel (Lloret et al., 2000; Punzón et al., 2004), loliginid and ommastrephid (Georgakarakos et al., 2002, 2006).

Songkhla Lagoon is one of the two lagoons in the world that has Irrawaddy dolphins, an endangered species. The lagoon's multitude of flora and fauna species makes it rich in biodiversity and it provides resources for local fisheries' fishermen all year around. The livelihood of the more than 1.9 million people of the 25 districts located in the three provinces of Southern Thailand rely on this fishery resource. The lagoon provides both economic benefits and nutrition for the local people. It is not only an important source of livelihood for men, but also for women, who do fish processing.

Small-scale fishing has been the main livelihood for local fishermen around Songkhla Lagoon for many generations. However, as in many places in the world, the numbers of fish have been declining sharply. Many fishermen of Songkhla Lagoon are wondering whether they can survive in fishing or if they must convert to another occupation. Many of them are moving to other fishing areas or changing their work.

For the effective socio-economic and environmental management of Songkhla Lagoon, and in aiming for sustainable development of fisheries' resources, it is vital to know the seasons and the trends of fish catch in the future, as well as the factors that affect any changes in these. Forecasting fish catch trends in Songkhla Lagoon is necessary.

There is a growing body of literature that recognizes the importance of statistical models in forecasting as well as in analyzing fish catches in Songkhla Lagoon over the last few decades. Significantly, Chesoh and Lim (2008) used a linear regression model for forecasting fish catches during 1977-2006. The structure of the fish community was analyzed using a clustering model (Chesoh and Choonpradub, 2011), the method for analyzing fish assemblage distribution (Chesoh and Choonpradub, 2009). However, historical time series fish catch data usually cover a long time, which includes seasonal and non-seasonal periods. The seasonal ARIMA model, therefore, is widely used for time series forecasting and resolves the problems of season and non-season of the data by describing the autocorrelations of the data.

Fish catch landing data depends not only on human activities, but also very much on the weather. Normally this data changes over time. Artificial neural network (ANNs) models were used in this study to compare with SARIMA models because ANNs have some advantage over other forecasting models. ANNs are powerful nonlinear regression techniques (Bishop, 1995; Ripley, 1996; Titterington, 2010). Nowadays, ANNs have been used widely in time series forecasting due to their ability to approximate various nonlinearities in the data (Zhang, 2003). The significant advantage of ANNs is no prior assumption of the model form is required in the model building process; moreover, the network model is mainly determined by the characteristics of the data. 
This study used monthly fish catch landings in Songkhla Lagoon data from 2003 to 2016 to evaluate the accuracy of SARIMA and ANNs models. The better model was chosen to forecast the fish and shrimp catch landing trends in Songkhla Lagoon to 2020.

\section{Materials and Methods}

\section{Study site and sample collection}

The total of fish and shrimp catch landings were collected for Songkhla Lagoon every month during 2003-2016 by the National Institute of Coastal Aquaculture (NICA), Thailand (Fig. 1).

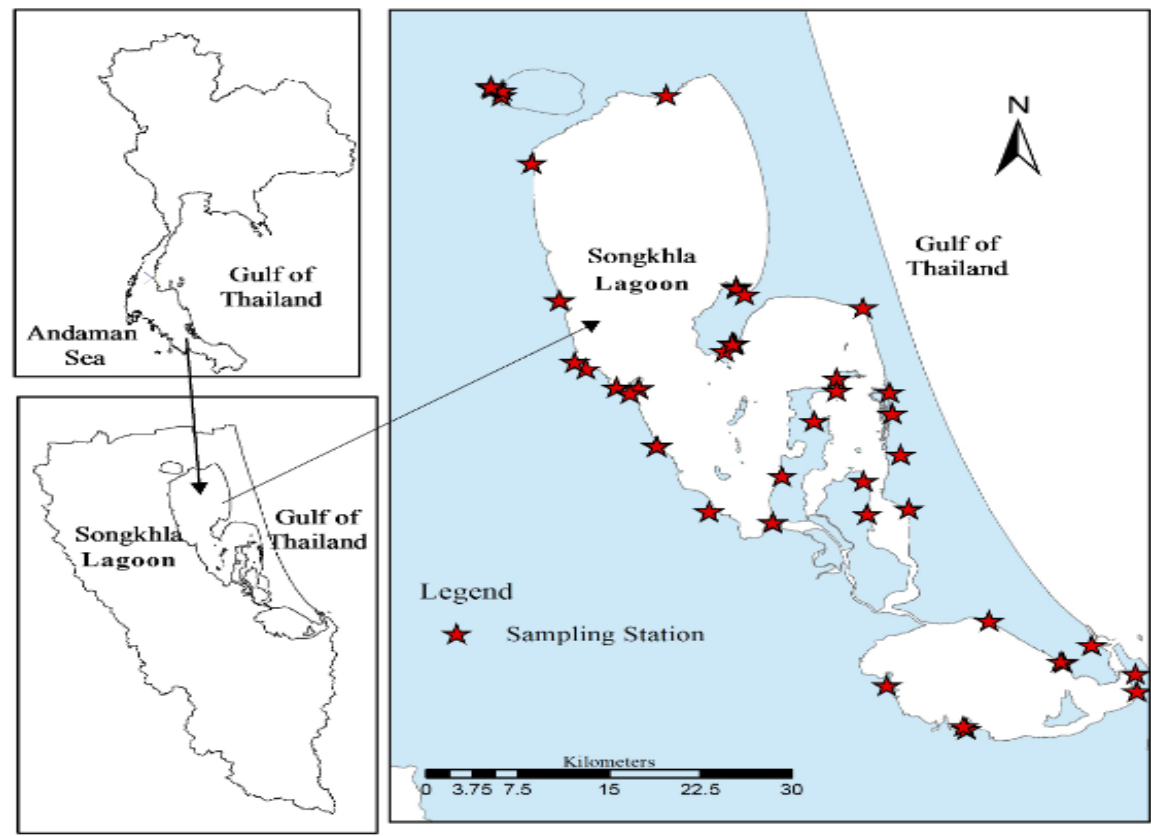

Figure 1. Sampling stations in Songkhla Lagoon

During 14 years of data collecting, 21 shrimp species and 158 fish species were collected every month in 37 stations around Songkhla Lagoon. The main types of fishing gear that have been used in Songkhla Lagoon include traps, set-bag nets and gill nets; and fishing activities that use such gear affect fish stock dynamics and the ecosystem (Chesoh and Choonpradub, 2011).

\section{Time series forecasting models}

SARIMA models

A time series $\left\{Z_{t} \mid t=1,2, \ldots, k\right\}$ is built using the $\operatorname{SARIMA}(p, d, q)(P, D, Q)$ s process with the mean $\mu$ of the Box and Jenkins (1976) time series model if

$$
\varphi(B) \phi\left(B^{s}\right)(1-B)^{d}\left(1-B^{s}\right)^{D}\left(Z_{t}-\mu\right)=\theta(B) \Theta\left(B^{s}\right) a_{t}
$$


where, $Z_{t}$ denotes the observed value at time $t, t=1,2, \ldots, k$ and $a_{t}$ is the estimated residual at time $t(E q .1) ; p, d, q$ denote the order of autoregressive (AR), degree of differencing or moving average (MA) of the non-seasonal part of the model to reach to stationary; $P, D, Q$ are autoregressive (AR), order or moving average (MA) of the seasonal part of the model; $s$ denotes the number of periods of the season;

$$
\begin{aligned}
& \varphi(B)=1-\varphi_{1} B-\varphi_{2} B^{2}-\ldots-\varphi_{p} B^{p}, \phi\left(B^{s}\right)=1-\phi_{1} B^{s}-\phi_{2} B^{2 s}-\ldots-\phi_{p} B^{p s}, \\
& \theta(B)=1-\theta_{1} B-\theta_{2} B^{2}-\ldots-\theta_{q} B^{q}, \text { and } \Theta\left(B^{s}\right)=1-\Theta_{1} B^{s}-\Theta_{2} B^{2 s}-\ldots-\Theta_{Q} B^{Q s}
\end{aligned}
$$

are polynomials in $B$ of degree $p, q, P$ and $Q ; B$ is the backward shift operator.

The SARIMA model includes four basic steps:

-Identification of the SARIMA $(p, d, q)(P, D, Q)$ s structure.

-Estimation of the unknown parameters.

-Goodness-of-fit tests on the estimated residuals (Box and Jenkins, 1976; Makridakis, 1990).

-Forecast future outcomes based on the known data.

The $a_{t}$ should be independently and identically distributed as normal random variables with mean $=0$ and variance $\sigma^{2}$. The roots of $\varphi(Z)=0$ and $\theta(Z)=0$ should all lie outside the unit circle. The SARIMA model should use at least 50, or preferably 100 observations (Box and Jenkins, 1976). This data includes more than 100 months, which is adequate for a proper time-series analysis (Tsitsika et al., 2007).

The autocorrelation (ACF) and partial autocorrelation functions (PACF) of a series together are the most powerful tool usually applied to reveal the correct values of the model parameters. The ACF gives the autocorrelations calculated at lags 1, 2 and so on, while PACF gives the corresponding partial autocorrelations, controlling for autocorrelations at intervening lags. Parameter estimation of tentative models was determined using maximum-likelihood methods. The results included the parameter estimates, standard errors, estimate of residual variance, standard error of the estimate, natural log likelihood Akaike's information criterion (AIC), and Schwartz's Bayesian criterion (SBC). Model selection was based on the minimization of AIC and SBC. These criteria were descriptors of the model's parsimony as they simultaneously account for the model's fit onto the observed series alongside the number of parameters used in the fit.

\section{Building SARIMA models}

Monthly fish and shrimp catch landing data during 2003-2016 in Songkhla Lagoon were divided into two data sets. The training data set was applied for the period (January 2003 to September 2015), and was transformed by taking the natural logarithm. The transformed data sets then were White Neural Network, tested for nonlinearity by the package "nonlinearityTseries" in R (Garcia, 2015). Both transformed shrimp and fish tests had $\mathrm{p}$ value $>0.05$, which means that there is no evidence to reject the null hypothesis of linearity (Varvey and Leybourne, 2007). The transformed training data of both shrimp and fish catch landings were tested for normality by using the Shapiro-Wilk normality test. The shrimp data test results were $\mathrm{w}=0.95967, \mathrm{p}$ values $>0.05$ and the fish data test results were $(\mathrm{w}=0.9843, \mathrm{p}$ values $>0.05)$. Therefore, the study had evidence to confirm that both transformed data sets 
were of normal distribution (Royston, 1995). Then, the data sets were tested the stationarity by the Box-Ljung test, Augmented Dickey-Fuller Test and KPSS Test. All these stationary test results had evidence to confirm that the transformed data of fish and shrimp catch landings were non-stationary time series; therefore, we can apply seasonal ARIMA models for forecasting shrimp and fish catches in the short term.

However, to get forecasts for shrimp and fish catch landings back to the original unit, the forecasted data were back-transformed after using a fitting model by taking exponentiation of the coefficients and the forecast is then the mean of the catches.

Twelve last months of data (October 2015 to September 2016) were used to validate the models.

The data was strongly seasonal and obviously non-stationary; therefore, seasonal differencing was used. The seasonally differenced monthly shrimp and fish catch landing data are shown in Fig. 2.

Seasonal differenced Shrimp catches

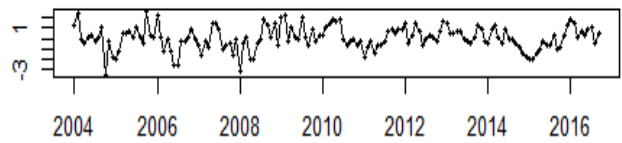

Year

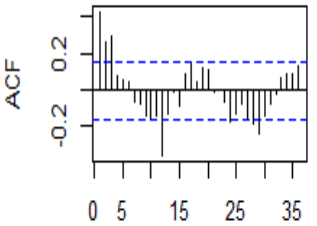

Lag

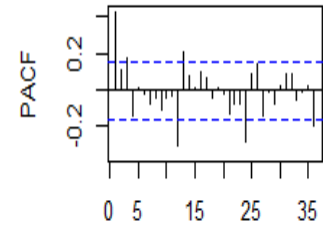

Lag
Seasonal differenced Fish catches

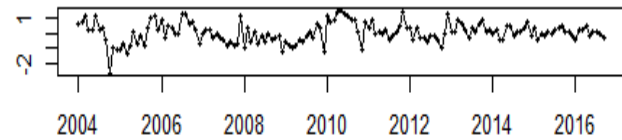

Year

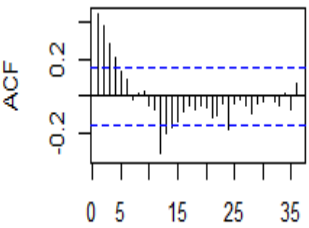

Lag

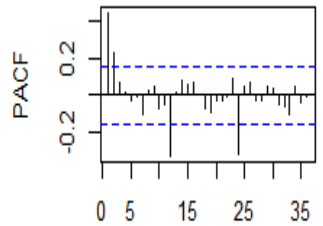

Lag

Figure 2. First differencing log monthly shrimp and fish catches landings data

The ACF and PACF of the transformed data sets showed spikes at periodic lags 12 and 24 (Fig. 2), which declined slowly, indicating that seasonal differencing was required to achieve stationary. Abrupt fluctuations in the seasonal ACF and PACF had been leveled out.

Based on the first differencing correlograms of autocorrelation (ACF) and partial autocorrelation (PACF) of natural $\log$ transformed data of shrimp and fish catch landings, this result was combined with the Akaike information criterion (AIC) to determine the best model. The values for SARIMA $(p, d, q)(P, D, Q)_{s}$ models were applied as follows:

- Shrimp catch landing, the SARIMA model $(1,1,2)(0,0,3)_{12}$ was considered as the most appropriate, and due to this model passing all required checks (all the spikes are now within the significant limits), the residuals appear to be white noise. A Ljung-Box test also shows that the residuals have no remaining autocorrelations; additionally, this model has the smallest AIC and RMSE and gives the smallest mean error (ME) (0.0456). This statement is shown in Fig. 3. 
Residual of Shrimp ARIMA model $(1,1,2)(0,0,3) 12$
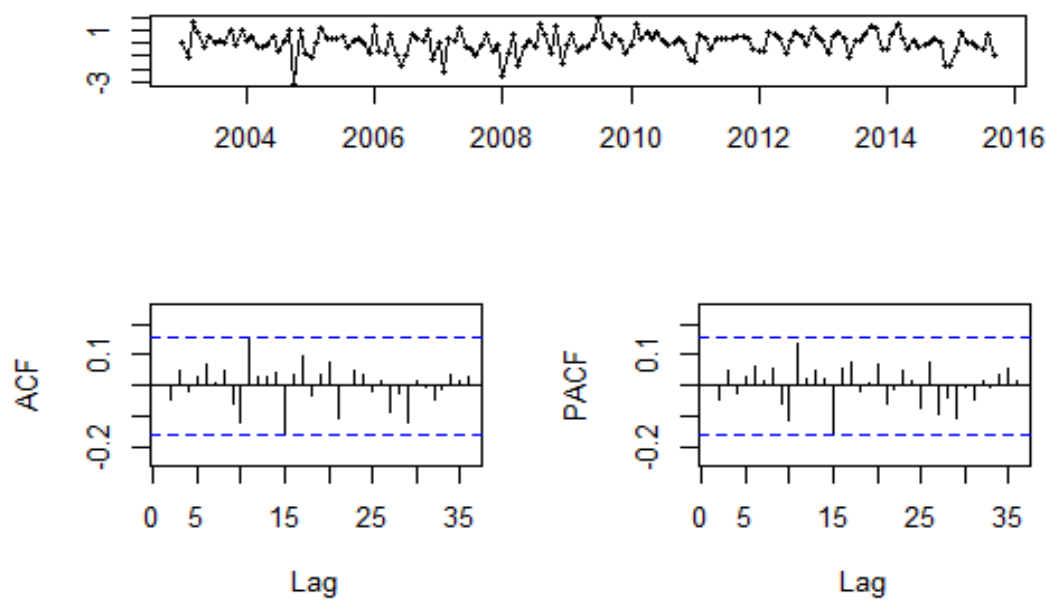

Figure 3. Residual of shrimp seasonal ARIMA model $(1,1,2)(0,0,3)_{12}$

- For fish catch landings, the seasonal ARIMA model $(1,1,1)(1,0,1)_{12}$ was considered as the most appropriate, due to this model having passed all requried checks (all the spikes are now within the significant limits, and the residuals appear to be white noise). A Ljung-Box test also shows that the residuals have no remaining autocorrelations. Jarque Bera Test result with $\mathrm{X}$-squared $=4.0196, \mathrm{df}=2$, p-value $=$ 0.134 means that the data is consistent with having skewness and excess kurtosis zero; as well as this, this model has the smallest AIC and RMSE and gives the smallest of mean errors (ME) (0.018). This declaration is shown in Fig. 4.

\section{Residuals of Fish ARIMA model $(1,1,1)(1,0,1) 12$}
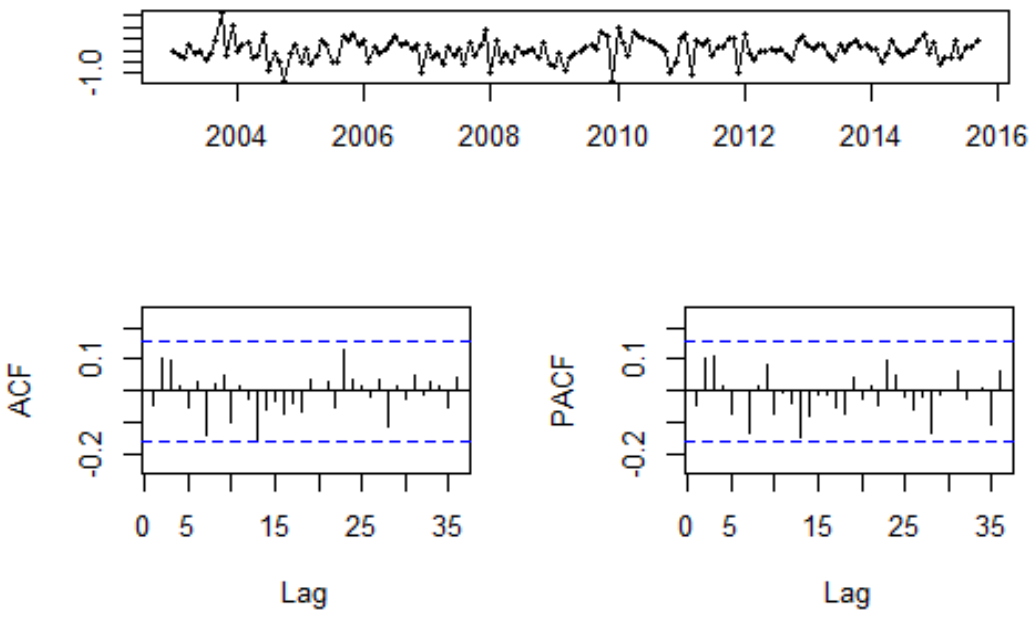

Figure 4. Residual of fish seasonal ARIMA model $(1,1,1)(1,0,1)_{12}$ 


\section{Artificial neural networks (ANNs)}

In this study we used single hidden layer feed forward network, this is the model form that is the most widely used for time series modeling and forecasting (Zhang et al., 1998). The model is described by a network of three layers of simple processing units connected by acyclic links. The relationship between the output $\left(y_{t}\right)$ and the inputs $\left(y_{t-1}, y_{t-2}, \ldots, y_{t-p}\right)$ follows the mathematical equation:

$$
y_{t}=\alpha_{0}+\sum_{j=1}^{q} \alpha_{j} g\left(\beta_{0 j}+\sum_{i=1}^{p} \beta_{i j} y_{t-i}\right)+\varepsilon_{t}
$$

where, $\quad \alpha_{j}(j=0,1,2, \ldots, q)$ and $\beta_{i j}(i=0,1,2, \ldots, p ; j=1,2, \ldots, q)$ are the model parameters, often called the connection weights; $p$ is the number of input nodes; and $q$ is the number of hidden nodes. The logistic function is often used as the hidden layer transfer function:

$$
g(x)=\frac{1}{1+\exp (-x)}
$$

Thus, the ANN model (2) in fact performs a nonlinear functional capturing from the past observations $\left(y_{t-1}, y_{t-2}, \ldots, y_{t-p}\right)$ to the future value $y_{t}$; therefore, $y_{t}$ can be written:

$$
y_{t}=f\left(y_{t-1}, y_{t-2}, \ldots, y_{t-p}, w\right)+\varepsilon_{t}
$$

where, $w$ is a vector of all parameters and $f$ is a function identified by the network structure and connection weights. Hence, the neural network is equivalent to a nonlinear autoregressive model. The Eq. 2 implies one output node in the output layer which is typically used for one step ahead forecasting.

\section{Building ANN model}

Like SARIMA model building, the training data set was natural logarithm transformed to get the best results and was used to build the ANN model, then the testing data was used to validate the model. While the SARIMA model uses one sample for model identification, estimation and evaluation, the ANNs estimated model is usually evaluated using a separate hold-out sample that is not displayed to the training process (Zhang, 2003). The model with the smallest mean squared error (MSE) will be chosen. The authors used the package nnfor (Nikolaos, 2017) from R software to create the ANNs model. The forecast statistical packages from $\mathrm{R}$ software were used to formulate the SARIMA models (Hyndman, 2017). All graphics and statistics were implemented by R software (R Core Team, 2018).

The best ANNs model was chosen to forecast shrimp fit with 5 hidden nodes and 20 repetitions, series modelled in differences: D1, univariate lags: $(1,2,3,4,5,6,7,10)$ due to its smallest MSE (0.0078). The procedure demonstration is expressed in Fig. 5. 


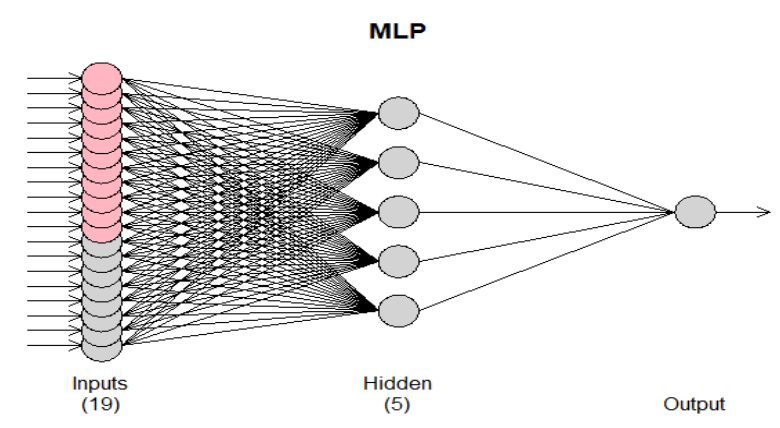

Figure 5. Structures of the best fitted Artificial neural network model for shrimp

The best ANNs model was chosen to forecast fish fit with 5 hidden nodes and 20 repetitions. Series modelled in differences: D1, univariate lags: $(1,2,3,4,5,6,7,8,12)$ due to its smallest MSE (0.0372) is shown in Fig. 6.

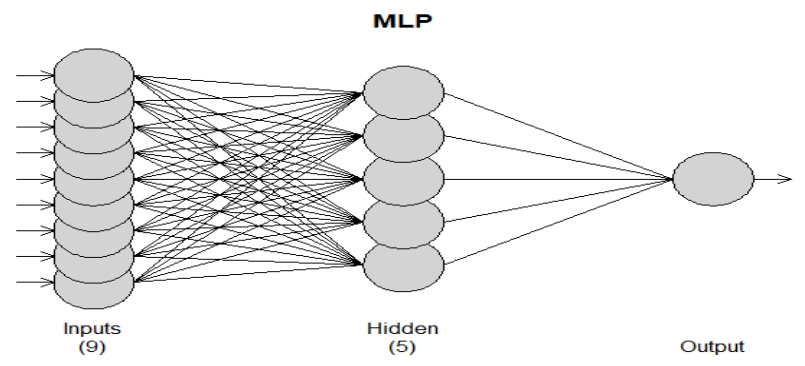

Figure 6. Structures of the best fitted artificial neural network model for fish

\section{Results}

\section{Comparison between the SARIMA and ANNs models}

To estimate the accuracy of the two models, the authors calculated the percentage improvement of SARIMA and ANNs models through Mean Absolute Error (MAE). The percentage MAE was calculated on the average over the validation samples of fish and shrimp catch landings from October 2015 to September 2016. The equation to measure percentage of MAE is as below:

$$
\operatorname{MAE}(\%)=\frac{1}{n} \sum_{i=1}^{n}\left(\frac{\left|y_{i}-\hat{y_{i}}\right|}{y_{i}}\right) \times 100 \%
$$

where, $\left|y_{i}-\hat{y_{i}}\right|$ is absolute difference between prediction and actual observation; $\mathrm{n}$ is the number of observations. The optimum model with the smaller percentage of MAE will be chosen for forecasting. The percentage MAE of SARIMA and ANNs models are shown in Table 1. 
Table 1. The percentage MAE values of shrimp and fish catch landings from chosen SARIMA models and ANNs during the period October 2015 to September 2016

\begin{tabular}{|c|c|c|c|c|c|c|c|c|c|c|}
\hline \multirow{2}{*}{ Months } & \multirow{2}{*}{$\begin{array}{c}\text { Shrimp } \\
\text { catches } \\
\text { landings } \\
\text { (tons) }\end{array}$} & \multicolumn{2}{|c|}{$\begin{array}{c}\text { SARIMA model } \\
\text { prediction } \\
(95 \% \text { CI }) \text {-mean }\end{array}$} & \multicolumn{2}{|c|}{ Neural Network prediction } & \multirow{2}{*}{$\begin{array}{c}\text { Fish } \\
\text { catches } \\
\text { landings } \\
\text { (tons) }\end{array}$} & \multicolumn{2}{|c|}{$\begin{array}{c}\text { SARIMA model } \\
\text { prediction } \\
(95 \% \mathrm{CI}) \text {-mean }\end{array}$} & \multicolumn{2}{|c|}{ Neural Network prediction } \\
\hline & & $\begin{array}{c}\text { Amount } \\
\text { (tons) }\end{array}$ & $\mid \%$ error $\mid$ & $\begin{array}{c}\text { Amount } \\
\text { (tons) }\end{array}$ & $\mid \%$ error $\mid$ & & $\begin{array}{c}\text { Amount } \\
\text { (tons) }\end{array}$ & |\% error| & $\begin{array}{c}\text { Amount } \\
\text { (tons) }\end{array}$ & $\mid \%$ error $\mid$ \\
\hline Oct 2015 & 60.52 & 47.22 & 21.97 & 45.75 & 24.41 & 114.50 & 76.83 & 32.90 & 101.33 & 11.50 \\
\hline Nov 2015 & 180.93 & 68.43 & 62.18 & 149.99 & 17.10 & 114.50 & 79.03 & 30.98 & 99.77 & 12.86 \\
\hline Dec 2015 & 41.5 & 37.41 & 9.85 & 19.00 & 54.22 & 63.27 & 71.54 & 13.07 & 66.26 & 4.73 \\
\hline Jan 2016 & 29.01 & 28.07 & 3.24 & 29.48 & 1.62 & 61.07 & 73.51 & 20.37 & 71.75 & 17.49 \\
\hline Feb 2016 & 34.68 & 29.18 & 15.85 & 20.57 & 40.69 & 54.19 & 62.78 & 15.85 & 70.31 & 29.75 \\
\hline Mar 2016 & 97.09 & 59.77 & 38.44 & 22.19 & 77.14 & 49.27 & 65.96 & 33.87 & 63.96 & 29.82 \\
\hline Apr 2016 & 129.39 & 60.17 & 53.50 & 24.69 & 80.92 & 59.03 & 64.26 & 8.86 & 44.87 & 5.84 \\
\hline $\begin{array}{l}\text { May } \\
2016\end{array}$ & 75.72 & 55.97 & 26.08 & 31.14 & 58.87 & 69.49 & 69.42 & 0.10 & 73.55 & 19.80 \\
\hline Jun 2016 & 78.32 & 38.56 & 50.77 & 10.60 & 86.47 & 60.29 & 64.20 & 6.49 & 72.23 & 22.81 \\
\hline Jul 2016 & 76.79 & 39.11 & 49.07 & 32.93 & 57.12 & 63.40 & 69.02 & 8.86 & 77.86 & 19.66 \\
\hline Aug 2016 & 50.44 & 51.59 & 2.28 & 31.66 & 37.23 & 63.28 & 69.65 & 10.07 & 75.72 & 5.70 \\
\hline Sep 2016 & 39.17 & 43.67 & 11.49 & 34.55 & 11.79 & 74.96 & 75.11 & 0.2 & 79.23 & 8.94 \\
\hline \multicolumn{3}{|c|}{ MAE (\%) } & 28.73 & & 45.63 & \multicolumn{2}{|c|}{ MAE (\%) } & 15.14 & & 16.70 \\
\hline
\end{tabular}


As can be seen from Table 1, the ANNs models used for forecasting shrimp and fish catch have higher percentage MAE than SARIMA models, especially in the shrimp data set. These results are clearly described by the amount of the fish and shrimp catch in validated data sets. These are shown in Fig. 7.

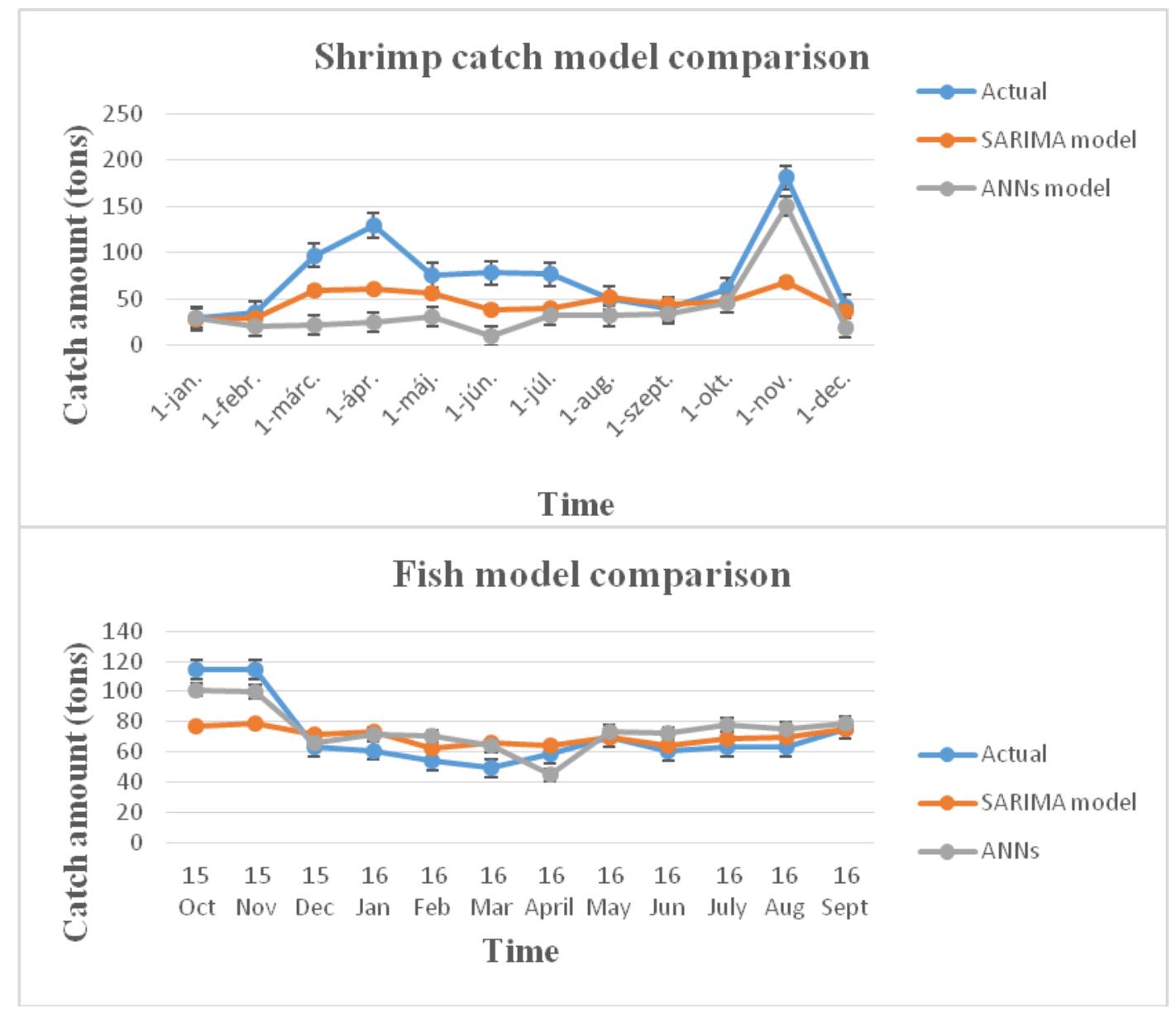

Figure 7. Fish and shrimp model comparisons

In both the shrimp and fish models, the 'forecast' line for the SARIMA model has the smaller distance, along with the Actual line, than the ANN model (Fig. 7). Therefore, this study uses SARIMA models for forecasting shrimp and fish catch landings in Songkhla Lagoon until 2020.

\section{Shrimp and fish catch landing trends in Songkhla Lagoon during 2016-2020}

The monthly catch landings of fish and shrimp groups during 2003-2016, fits and forecasts for coming years, that were produced by the best fitting and best seasonal ARIMA forecasting model per group species, are shown in Fig. 8. Overall, the amplitude and the duration of the between-month fluctuations are adequately described and forecasted by the model with few exceptions. 
Shimp catches in Songkhla lagoon to 2020

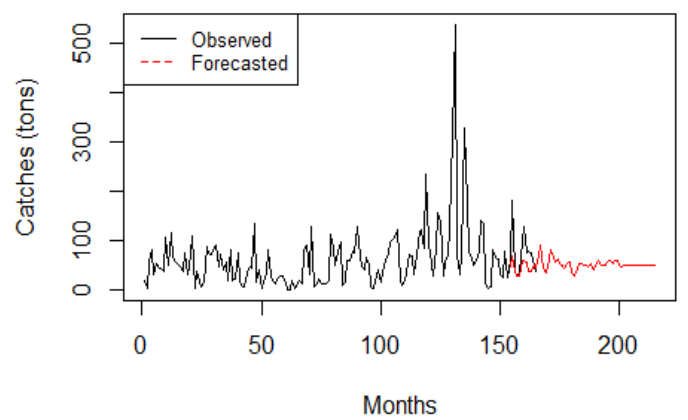

Fish catches in Songkhla lagoon to 2020

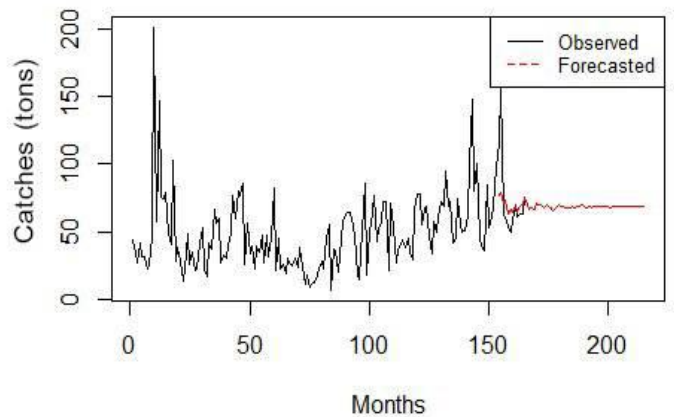

Figure 8. Shrimp and fish catch forecasted in Songkhla Lagoon to 2020

The result of shrimp and fish catch landings to 2020 is shown in the Fig. 8. It can be seen clearly that, during the period between 2017 and 2020, the shrimp catch landing in Songkhla Lagoon fluctuates at around 53 tons per month, compared with the mean catch (62.5 tons per month) during 2003-2016. Moreover, the fish catch will be around 68 tons per month, compared with the mean catch of around 49 tons during the period 2003-2016. The detailed trends of fish and shrimp catch landings in Songkhla Lagoon until 2020 are clearly described in Fig. 9.
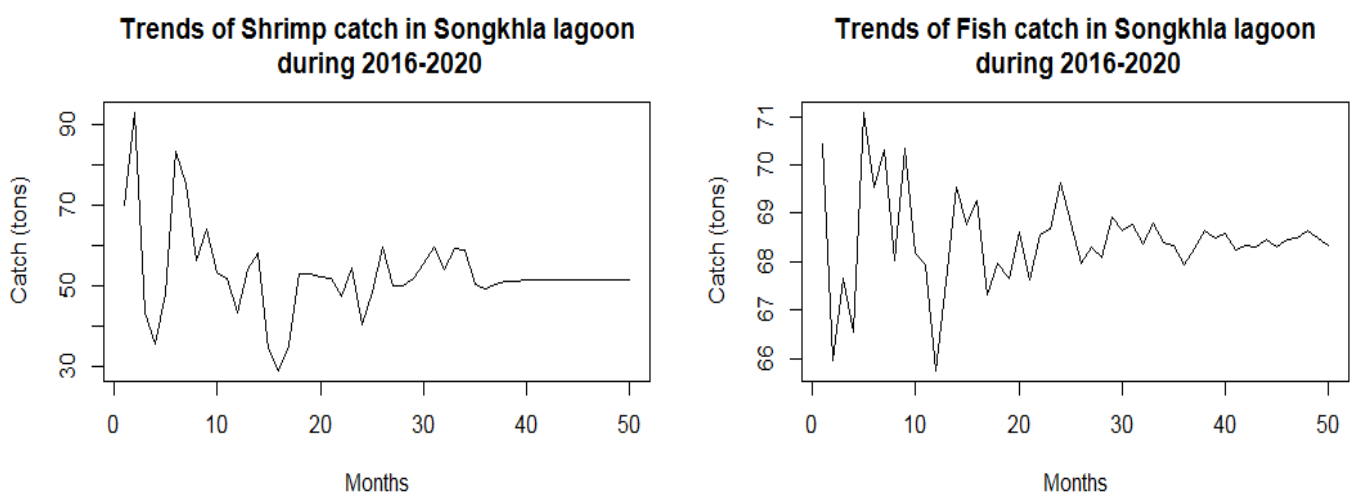

Figure 9. Shrimp and fish catch forecasted for Songkhla Lagoon during 2016- 2020

In Fig. 9, the fluctuations of the shrimp and fish catch landings during 50 upcoming months are somehow similar. During the two first years (from month 1 to month 24), the catch amount fluctuated sharply between months; after that, the catch amount was more stable. The difference between the lowest and highest catch amounts of shrimp are significant bigger than for fish. The lowest shrimp catch was January 2018 (28.95 tons) and the highest catch in November 2016 (92.94 tons), the difference being approximately 64 tons. The lowest fish catch was September 2017 (65.75 tons) and the highest fish catch was February 2017 (71.08 tons), with a difference of only 5.33 tons. 


\section{Seasonal factor}

The overview of monthly shrimp and fish catch landings in Songkhla Lagoon during 2003-2016 are presented in Fig. 10.

Fish and shirmp catch landing (in tons)

in Songkhla lagoon during 2003-2016

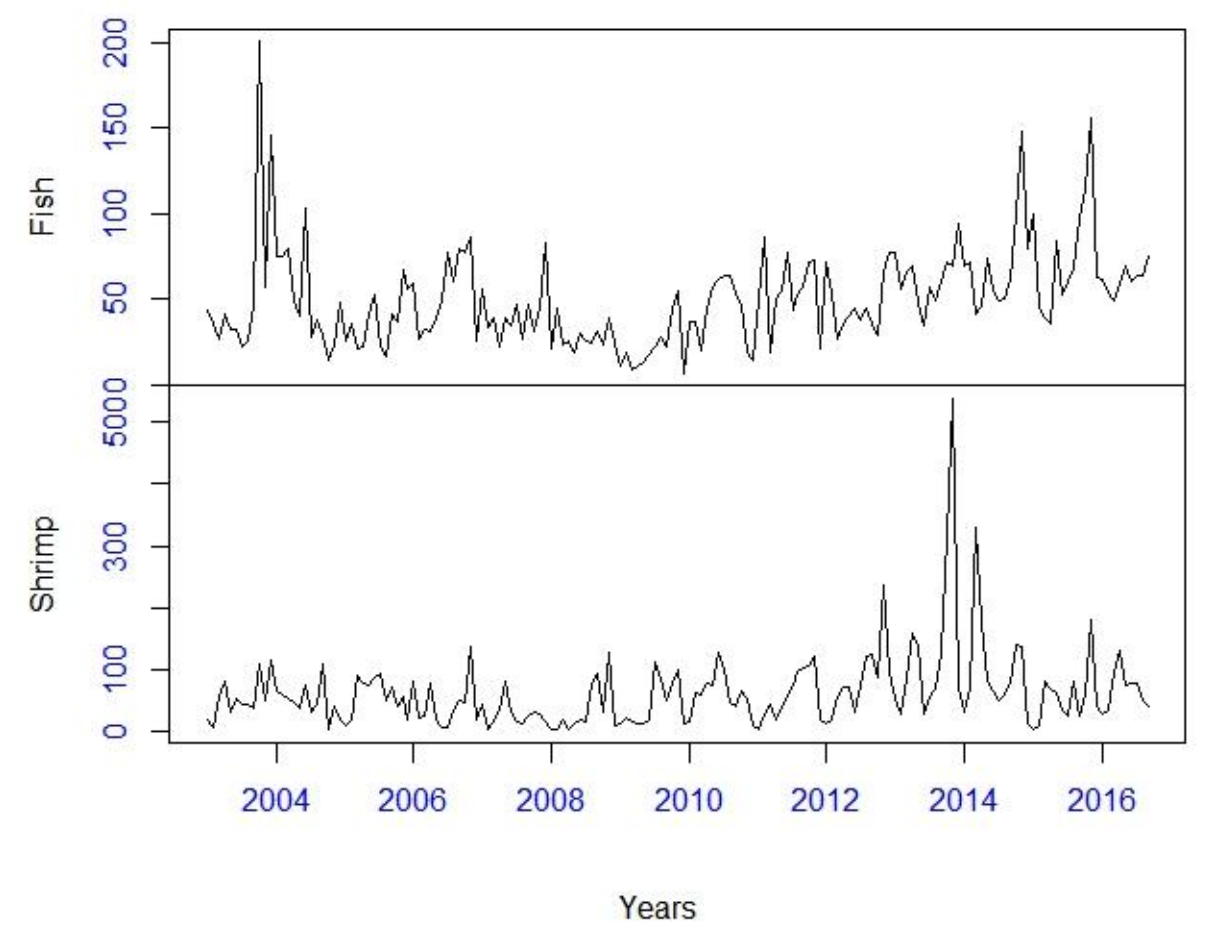

Figure 10. Monthly shrimp and fish catch landings in Songkhla Lagoon during 2003-2016

As shown in Fig. 10, the lowest shrimp catch landing was in January 2008, with only 1.77 tons; and the highest catch amount was in November 2013, the shrimp catch reached a peak with 537.41 tons. The mean shrimp catch was estimated at around 62.56 tons. The results obtained for the monthly fish landings were also shown in Fig. 2, when the most significant catch amount topped 200.78 tons in October 2003; and the lowest in this 2003-2016 period was in December 2009 (6.96 tons). The average monthly catch was around 50.31 tons for this period.

Using Seasonal Factors is the way to analyze data to reveal regular recurring changes associated with the calendar. A seasonal factor measures the percentage amount when, on average, a month is higher or lower than normal (Austin, 1981). From Fig. 10, it can be seen that the size of the seasonal fluctuations in both shrimp and fish time series data seems to be roughly constant over time, and does not depend on the level of the time series. Thus, to know exactly the seasonal trend of monthly shrimp and fish catches, the study estimated seasonal factors affecting shrimp and fish for the particular month from January to December. These factors are the same for each particular month, each year. Before monsoon season in Southern Thailand, December, is the best season for both shrimp and fish catching, which is shown by the high seasonal factors (from September 
to November). However, during monsoon season (December to February), the seasonal factors for shrimp catch landings are significant low while the factors for fish catch are really low during the dry season (March to May). The details for these claims are given in Table 2 and Fig. 11. November provides the best seasonal factors for both shrimp catch landings (about 0.88) and fish (about 0.31); while the lowest seasonal factor for shrimp catch (about -0.96) is in January, and for the fish catch (about -0.36) in March, indicating that there seems to be a peak in both shrimp and fish catch landings in November with the bottom for shrimp catch in January, and for the fish catch in March in each year.

Table 2. Seasonal factors for shrimp and fish catch in Songkhla Lagoon during 2003-2016

\begin{tabular}{c|c|c}
\hline Months & Shrimp seasonal factors & Fish seasonal factors \\
\hline January & -0.96 & 0.09 \\
February & -0.76 & 0.03 \\
March & 0.20 & -0.36 \\
April & 0.14 & -0.23 \\
May & 0.13 & -0.03 \\
June & -0.10 & 0.09 \\
July & -0.005 & -0.08 \\
August & 0.30 & -0.10 \\
September & 0.41 & 0.09 \\
October & 0.33 & 0.19 \\
November & 0.88 & 0.31 \\
December & -0.59 & -0.01 \\
\hline
\end{tabular}
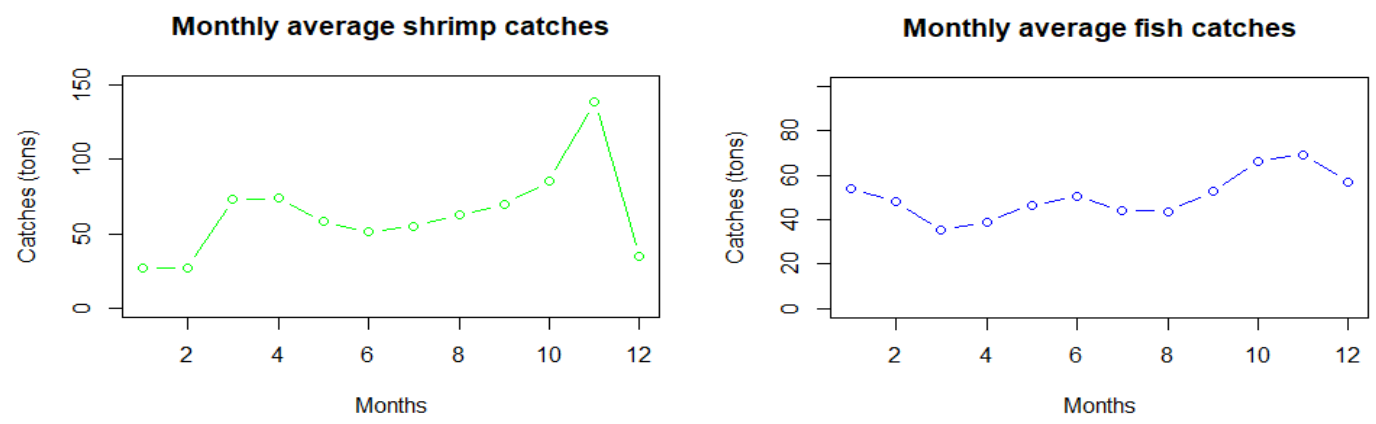

Figure 11. The average catch of fish and shrimp per month in Songkhla Lagoon during 20032016

According to the data for the total fish and shrimp catch from January to December for January 2003 through to the first 9 months of 2016, the total catch in months of the two species was different with reference to both the amount and the time of catch in the year. The amount of shrimp caught was lowest in January (estimate 27.06 tons) and highest in November, up to 138.55 tons. The amount of fish caught was lowest in March (only 35.13 tons) and highest in November, around 69.36 tons. In general, there was a sharp fluctuation in the average catch between months in year, particularly with reference to shrimp catch landings.

The trend and season of monthly shrimp and fish catch landings is shown clearly in Fig. 12. 
Decomposition of additive time series

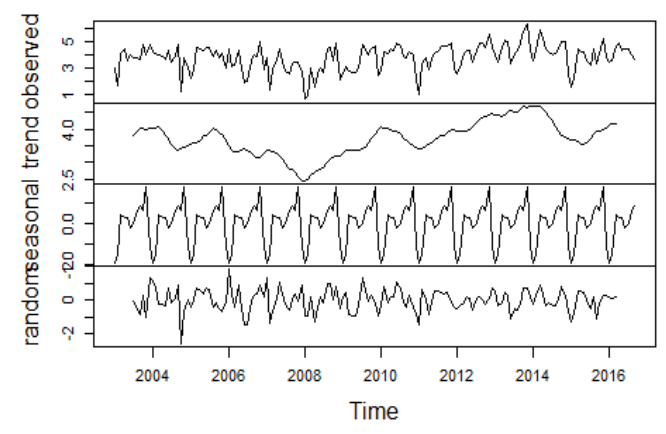

a.Shrimp catches
Decomposition of additive time series

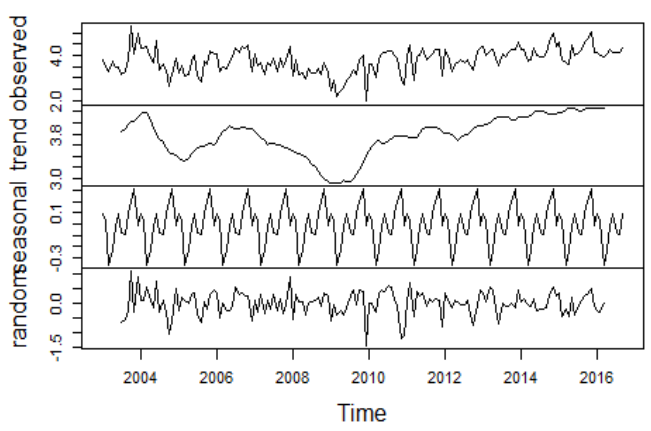

b.Fish catches

Figure 12. Trend and season of monthly shrimp and fish catch landings in Songkhla Lagoon during 2003-2016

\section{Discussion}

\section{Model fitting and forecasting performances}

In this study, the percentage improvement figures for SARIMA and the ANN model for shrimp catch are significantly different (16.9\%). In contrast with this result, the improvement figures for fish are very little different (1.56\%). In the past, the percentage improvement of ARIMA and the ANN model has been different according to the data set and the period of the forecasting, which was confirmed by Khashei and Bijari (2011) when they used sunspot, Canadian lynx, and exchange rate data sets to compare percentage improvements of ARIMA and the ANN model. Almost all the results showed the better percentage improvement for ANNs over the ARIMA model at different levels. However, when they forecasted 67 points ahead from sunspot data set, percentage MAE of ANNs model is $3.32 \%$ bigger than ARIMA model. Again, this statement was proved by Tseng et al. (2002), when the SARIMA model of machinery production time series showed the better result compared to the neural network (NN) with 60 historical forecasting items of data, but the SARIMA model's results were not as good as NN when they forecast 36 points ahead.

In the past, Stergiow (1989) found two suitable ARIMA models to forecast pilchard (sardina pilchardus) catches up to 12 months ahead with mean errors (ME) of $14.6 \%$ and $12 \%$ for the two models. Suitable SARIMA models were found in this study for shrimp and fish with mean errors of $4.56 \%$ and $1.83 \%$.

Univariate SARIMA models satisfactorily predicted the total fish and shrimp catch landings. So far, linear regression models developed for total fish catch in Songkhla Lagoon have illustrated little forecasting power (the percentage improvement was 34.6\%) (Chesoh and Lim, 2008). In the present study, the univariate SARIMA models that were built show good performance in terms of explained variability and predicting power. The results demonstrate a strong autoregressive character of the time series, i.e. the fish catch landing value at month $t$ depends on the catch at month $t-12$. SARIMA models provided satisfactory forecasts that were close to the recorded fish and shrimp catch values. The seasonal ARIMA models were found not to be appropriate for both shrimp and fish catch landing, suggesting that the catch landings of fish and shrimp had a different statistical structure. The present findings also imply the clear existence of a 
seasonal pattern in the monthly fish/shrimp catch landing, which is shown both in the original data and seasonal factor (Table 2 and Fig. 11).

\section{Seasonal fish and shrimp catch landing}

There are major peaks for seasonal fish and shrimp catch landing in the rainy season (from September to November), however, they quickly reduce in December-January. The seasonal cycle is most likely related to the nature of the lagoon ecosystem. In the monsoon seasons (October-January), there is intrusion of sea water from the Gulf of Thailand into the lagoon through a short narrow channel (about $8 \mathrm{~m}$ in depth) in the outer section. Where the most intensive fishing activities occur, the average depth is very shallow, 1.0-1.5 m. The dry season in southeast Thailand extends from February to April. Most of the brackish and saltwater fish populations migrate to the open sea, whereas the freshwater fish in the upper lake migrate to deeper pools. This phenomenon is consistent with the seasonal migration of some fishermen to find work in the cities (Chesoh and Lim, 2008). The fishing is more intense during the first months of the monsoon season and decreases in December, due to such heavy rain and flooding that the fishermen cannot go fishing. The seasonal catch of shrimp and fish during 20032016 was different: while the shrimp catch decreased sharply from December to February, the fish catch decreased significant in the dry season, mostly concentrated in March to May, and before the rainy season (July and August). During the dry season, the fish from Songkhla Lagoon migrate back to the sea (the Gulf of Thailand) for breeding, spawning and larval nursing (Choonhapran, 1996; Chesoh and Samphantharaga, 2004). This claim is also confirmed by the composition of the first finding species found in both Songkhla Lagoon and Sathing Pra (a coastal area in Songkhla province that the author is studying). The seasonal shrimp catch landing is somehow different from the seasonal fish catch, the explanation coming from the effect of the restocking program during this period.

Factors involved in the seasonal variation in fish and shrimp catches may be due to regional climate, especially the effect of the monsoon season in the Southern Thailand, for during these months, the catch in coastal provinces decreases sharply (Komontree et al., 2006), and the catch in the lagoon tends to increase. Seasonal difference effects on monthly fish catch also have been found in previous studies (Stergiou and Christou, 1996; Komontree et al., 2006). Even though the fish catch is very low during March to May, the shrimp catch tends to increase which may be due to the effect of seasonal difference, as the annual closure of the fishing area of the Gulf of Thailand from February 16 to May 15 does not affect the fish catch in the lagoon. The changes of season lead to the changes in zooplankton (Brysiewicz et al., 2006), which would be one of the reasons for the difference in fish and shrimp catch between seasons.

\section{Fish and shrimp catch trends in Songkhla Lagoon}

In the monthly fish and shrimp catch landings until 2020, both shrimp and fish catch fluctuated sharply during the two first years of forecasting, then they fluctuated steadily. The shrimp catch reduced to 52.88 tons, by around $15.47 \%$ of the catch average during 2003-2016. In contrast with the shrimp catch, the fish catch increased to 68.45 tons, estimated at a $36.05 \%$ increase in comparison with the mean fish for the same period in 2003-2016. This result reflects the reality of fishing activities in Songkhla: the general trends of shrimp catch reduce due to the decrease in the number of juvenile shrimps from the stocking program. 
During the past four decades, only two papers have reported the annual catches in the main Songkhla Lagoon. The first study was conducted during 1984-1986 (Tonkwinas et al., 1986) and the second during 1994-1995 (Choonhapran et al., 1996). These studies reported the total annual fish catch during 1994-1995, a decrease of $22 \%$ compared to the catch in 1984-1986. The monthly report of total fish catches during 1977 to 2006 was 219.9 tons (Chesoh and Lim, 2008).

\section{Conclusion}

Knowing the seasons and forecasting both play an important role in fisheries' management, as they constitute the first steps of the planning and decision-making process (Stergiou and Christow, 1996; Stergiou et al., 1997). The facts of the good performance of the final ARIMA models applied to shrimp and fish catch landings in this paper in terms of short term forecasting of up to 12 months in advance, as well as the results that the models provided for insight into the seasonal components of the time series, all justify their use in fisheries' management. Accurate forecasts for 1-2 years may provide useful information to fishery policy makers as well as fishermen. For small scale fishing, the conditions for fishing do not seem to change much inside the lagoon and there are limited budgets for organizing the usual surveys, so SARIMA models can be considered as suitable tools to forecast the persistence of fish and shrimp catches. The performance of the models could be improved by additional information about environmental factors (e.g. temperature, salinity...) and other factors (market prices and biological information) put into the multivariate models.

Acknowledgments. This paper has been partly prepared with the support from the Higher Education Research Promotion and the Thailand's Education Hub for the Southern Region of ASEAN Countries Project Office of the Higher Education Commission. Financial support was granted by the Graduate School, Prince of Songkla University, Thailand. The authors would like to thank the National Institute of Coastal Aquaculture (NICA) staff for giving them the chance to join in data collection and for providing data for the research.

Conflict of interest. The authors definitely confirm that there is no conflict of interest concerning this article.

\section{REFERENCES}

[1] Austin, J. S. (1981): How to use and interpret seasonal factors. - Business Economics 16(4): 40-42.

[2] Bishop, C. (1995): Neural Networks for Pattern Recognition. - Oxford University Press.

[3] Box, G., Jenkins, G. M. (1976): Time Series Analysis, Forecasting and Control. Holden-Day, San Francisco, CA.

[4] Brysiewicz, A., Slugocki, L., Wesolowski, P., Czerniawsky, R. (2006): Zooplankton community structure in small ponds in relation to fish community and environmental factors. - Applied Ecology and Environmental Research. 15(4):929-941, DOI: 10.15666/aeer/1504_929941.

[5] Chesoh, S., Samphantharaga, U. (2004): Assessment of fisheries resources and socioeconomics of fisheries households in floodplain area of Songkhla province. - J Agric Res Ext. 22, 118-25. 
[6] Chesoh, S., Choonpradub, C. (2009): Method for Analyzing Fish Assemblage Distribution with Application to Fishery Landings of Tropical Shallow Lake as Songkhla Lake, Thailand. - Modern Applied Science 3(5): 179-192.

[7] Chesoh. S., Choonpradub, C. (2011): A Model for Clustering Fish Community Structure with Application to Songkhla Lake Bi-monthly Catches 2003 -2006. - Turkish Journal of Fisheries and Aquatic Sciences 11(2): 177-184, DOI: 10.4194/trjfas.2011.0201.

[8] Chesoh, S., Lim, A. (2008): Forecasting fish catches in the Songkhla Lake basin. ScienceAsia 34(3): 335-340, DOI: 10.2306/scienceasia1513-1874.2008.34.335.

[9] Choonhapran, A. (1996): Study on fisheries resources and population changes in Songkhla Lake: Case study on 3 fishing gears. - Technical Paper 18/1996: 54, National Institute of Coastal Aquaculture (NICA), Songkhla (in Thai, with English abstract).

[10] Choonhapran, A., Rattanachai, C., Meechukan, A. (1996): Evaluation of fish catch in Songkhla lake during 1994-1995. - Technical Paper 4/1996, National Institute of Coastal Aquaculture (NICA): 1-53, Songkhla.

[11] Fox, W. Jr. (1970): An Exponential Surplus-Yield Model for Optimizing Exploited Fish Populations. - Transactions of the American Fisheries Society (99:1): 80-88, DOI: $10.1577 / 1548-8659(1970) 99<80$.

[12] Fritsch, S., Guenther, F. (2016): Neuralnet: Training of Neural Networks, R package version 1.33, URL: https://CRAN.R-project.org/package=neuralnet.

[13] Garcia, C. A. (2015): nonlinearTseries, Nonlinear Time Series Analysis. R package version

[14] 0.2.3, URL: https://CRAN.R-project.org/package=nonlinearTseries.

[15] Georgakarakos, S., Haralabous, J., Valavanis, V., Arvanitidis, C., Koutsoubas, D., Kapantagakis, A. (2002): Loliginid and ommastrephid stock prediction in greek waters using time series analysis techniques. - Bulletin of Marine Science 71(1): 269-287.

[16] Georgakarakos, S., Koutsoubas, D., Valavanis, V. (2006): Time series analysis and forecasting techniques applied on loliginid and ommastrephid landings in Greek waters. Fisheries Research 78(1): 55-71, DOI: 10.1016/j.fishres.2005.12.003.

[17] Harvey, D. I., Leybourne, S. J. (2007): Testing for time series linearity. - Econometrics Journal 2007 (10): 149-165, DOI: 10.1111/j.1368-423X.2007.00203.x.

[18] Khashei, M., Bijari, M. (2011): A novel hybridization of artificial neural networks and ARIMA models for time series forecasting. - Applied Soft Computing 2011(11): 26642675, DOI: $10.1016 / \mathrm{j} / \mathrm{asoc} .2010 .10 .015$.

[19] Komontree, P., Tongkumchum, P., Karntanut, W. (2006): Trends in marine fish catches at Pattani Fishery Port (1999-2003). - Songklanakarin J. Sci. Technol 28(4): 887-895.

[20] Kourentzes, N. (2017): nnfor: Time Series, Forecasting with Neural Networks, R package version 0.9.2, URL: https://CRAN.R-project.org/package=nnfor.

[21] Koutroumanidis,T., Iliadis, L., Sylaios, G. K. (2006): Time-series modeling of fishery landings using ARIMA models and Fuzzy Expected Intervals software. - Environmental Modelling and Software 21(12): 1711-1721, DOI: 10.1016/j.envsoft.2005.09.001.

[22] Lloret, J., Lleonart, J., Solé, I. (2000): Time series modelling of landings in Northwest Mediterranean Sea. - ICES Journal of Marine Science 57(1): 171-184, DOI: 10.1006/jmsc.2000.0570.

[23] Makridakis, S. G. (1990): Forecasting Planning and Strategy for the 21st Century. Collier Macmillan Publishers, London.

[24] Murawski, S. A., Lange, A. M., Sissenwine, M. P., Mayo, R. K. (1983): Definition and analysis of multispecies otter-trawl fisheries of the northeast coast of the United States. ICES Journal of Marine Science 41 (1): 13-27, DOI: 10.1093/icesjms/41.1.13.

[25] Pauly D. (1989): Biology and management of tropical marine fisheries. - Resource Management and Optimization 6(3): 253-271.

[26] Pierce, G. J., Boyle, P. R. (2003): Empirical modelling of interannual trends in abundance of squid (Loligo forbesi) in Scottish waters. - Fisheries Research 59(3): 305-326, DOI: 10.1016/S0165-7836(02)00028-0. 
[27] Punzón, A., Villamor, B., Preciado, I. (2004): Analysis of the handline fishery targeting mackerel (Scomber scombrus, L.) in the North of Spain (ICES Division VIIIbc) . Fisheries Research 69(2): 189-204, DOI: 10.1016/j.fishres.2004.05.002.

[28] R Core Team. (2018). R: A language and environment for statistical computing. - R Foundation for Statistical Computing, Vienna, Austria, URL: https://www.Rproject.org/.

[29] Ripley, B. (1996): Pattern Recognition and Neural Networks. - Cambridge University Press.

[30] Royston P. (1995): Remark AS R94: A Remark on Algorithm AS 181: The W-test for Normality. Journal of the Royal Statistical Society. - Series C (Applied Statistics) 44 (4): 547.

[31] Sparre, P., Ursin, E., Venema, S. C. (1989): Introduction to tropical fish stock assessment. Part I - Manual. - FAO Fisheries Technical Paper 301(1): 337.

[32] Stergiou, K. I. (1989): Modelling and forecasting the fishery for pilchard (Sardina pilchardus) in Greek waters using ARIMA time-series models. - ICES Journal of Marine Science 46(1): 16-23, DOI: 10.1093/icesjms/46.1.16.

[33] Stergiou, K. I. (1990): Prediction of the Mullidae fishery in the eastern Mediterranean 24 months in advance. - Fisheries Research 9(1): 67-74, DOI: 10.1016/01657836(90)90041-S.

[34] Stergiou, K. I., Petrakis, G. (1993): Description, assessment of the state and management of the demersal and inshore fisheries resources in the Hellenic Seas. - Fresenius Environmental Bulletin 2: 312-319.

[35] Stergiou, K. I., Christou, E. D. (1996): Modelling and forecasting annual fisheries catches: comparison of regression, univariate and multivariate time series methods. Fisheries Research 25(2): 105-138, DOI: 10.1016/0165-7836(95)00389-4.

[36] Stergiou, K. I., Christou, E. D., Petrakis, G. (1997): Modelling and forecasting monthly fisheries catches: Comparison of regression, univariate and multivariate time series methods. - Fisheries Research 29(1): 55-95, DOI: 10.1016/S0165-7836(96)00482-1.

[37] Titterington, M. (2010): Neural Networks. - Computational Statistics 2(1): 1-8.

[38] Tookwinas, S., Sirimontraporn, P., Chaiwachakul, S., Yupensuk, K. (1986): Survey on efficiency of fishing gear and evaluation of fisheries resources utilization in Songkhla lake. - Technical Paper 12/1986: 1-13, National Institute of Coastal Aquaculture (NICA), Songkhla (in Thai, with English abstract).

[39] Tsenga, F. M., Yub, H. C., Tzeng, G. H. (2002): Combining neural network model with seasonal time series ARIMA model. - Technological Forecasting \& Social Change 2002(69): 71-87, DOI: 10.1016/S0040-1625(00)00113-X.

[40] Tsitsika, E. V., Maravelias, C. D., Haralabous, J. (2007): Modeling and forecasting pelagic fish production using univariate and multivariate ARIMA models. - Fisheries Science 73(5): 979-988, DOI: 10.1111/j.1444-2906.2007. 01426.x551.

[41] Zhang, G. P. (2003): Time series forecasting using a hybrid ARIMA and neural network model. - Neuro computing 50(2003): 159-175.

[42] Zhang, G. P., Patuwo, E. B., Hu, M. Y. (1998): Forecasting with artificial neural networks: the state of the art. - J. Forecasting 14 (1998): 3-13. 